\title{
Early Neurobehavioral Development of Preterm Infants
}

\author{
Desenvolvimento Neurocomportamental Inicial de Bebês Prematuros
}

\author{
Paula Stefaneli Ziotti Gabriel ${ }^{a}$, Cibelle Kayenne Martins Roberto Formiga ${ }^{b}$ \\ \& Maria Beatriz Martins Linhares*, a \\ ${ }^{a}$ Universidade de São Paulo, Ribeirão Preto, Brasil \\ $\&^{b}$ Universidade Federal de Goiás, Goiânia, Brasil
}

\begin{abstract}
The aim of the present study was to assess the very early neurobehavioral development of preterm infants and to examine differences regarding sex. Two-hundred and two preterm infants were assessed by the Neurobehavioral Assessment of the Preterm Infant (NAPI), which was carried out at 32-37 weeks postconceptional age in the hospital setting. The infants' performance was compared to a norm-referenced sample and a comparison between groups regarding sex was also done. In comparison to the NAPI normreference, the preterm infants showed less muscular tonicity on the scarf sign, less vigor and spontaneous movement, higher alertness and orientation, weaker cry, and more sleep state. There was no statistical difference between males and females preterm infants at NAPI performances.

Keywords: Preterm, neurobehavioral, sex.

\section{Resumo}

O objetivo do estudo foi avaliar o desenvolvimento neurocomportamental inicial de bebês prematuros e examinar as diferenças quanto ao sexo. Foram avaliados 202 bebês nascidos pré-termo pela Avaliação Neurocomportamental para Prematuros (NAPI), que foi realizada na fase de 32-37 semanas de idade pósconcepcional no contexto hospitalar. O desempenho dos bebês no NAPI foi comparado com a amostra de padronização do instrumento e também foi feita a comparação entre grupos diferenciados pelo sexo. Em relação à amostra de padronização, os bebês deste estudo apresentaram menor tonicidade muscular no sinal de cachecol, menor vigor e movimento espontâneo, mais alerta e orientação, choro mais fraco e mais estado de sono. Houve um padrão semelhante de desempenho neurocomportamental dos meninos e meninas nascidos prematuros.

Palavras-chave: Prematuro, neurocomportamental, sexo.
\end{abstract}

Scientific and clinical advances in Perinatology and Neonatology have enhanced the chances of survival of preterm and very low birth weight neonates. Consequently, clinical and ethical demands have emerged regarding the early assessment of these vulnerable children in order to detect high-risk markers for developmental problems (Roze, Kerstjens, Maathuis, Horst, \& Bos, 2008).

Follow-up programs for preterm and low birth weight infants have been recommended to begin immediately post-discharge and focus on the assessment, promotion,

\footnotetext{
"Endereço para correspondência: Faculdade de Medicina, Laboratório de Pesquisa em Prevenção de Problemas de Desenvolvimento e Comportamento da Criança, Universidade de São Paulo, Prédio da Saúde Mental, Campus Universitário Monte Alegre, Avenida Tenente Catão Roxo, 2650, Ribeirão Preto, SP, Brasil 14051-140. Tel.: 55 (country code) 16 (city code) $36024610 /$ 36372702. Fax: 55-16-36024607/36024504. E-mail: linhares@fmrp.usp.br

This study was supported by the National Council for Development Science and Technology $(\mathrm{CNPq})$. The authors wish to thank the staff of the Infant Maternity Hospital of Goiania, the undergraduate team of the "Follow-up of Infants at Risk Study," and the families for allowing their infants to participate in this study.
}

protection, and monitoring of these infants' health and developmental outcomes (Koldewijn et al., 2009; Reuner, Hassenpflug, \& Philippi, 2009). There are several clinical assessments aimed at evaluating the health status of the infants within the first postnatal hours such as the Apgar score, Clinical Risk Index for Babies (CRIB; Cockburn et al., 1993), Neonatal Medical Index (Korner et al., 1994) and Score for Neonatal Acute Physiology (SNAPP II; Gray, Richardson, \& McCormick, 1992). These validated measurements have been used in the prediction of health status of preterm infants and have been proposed to aid in approximating the morbidity and mortality rates of this vulnerable population. There also exist developmental scales focusing on infants' motor and mental development assessment during the first years of postnatal age, such as the Bayley Scales (Bayley, 1993) and The Alberta Infant Motor Scale (AIMS; Piper, Pinnell, Darrah, Maguire, \& Byrne, 1992). Psychomotor development, as assessed by the Bayley Motor Scale at 2.5 years of age, gestational age $<30$ weeks, male sex, and intraventricular hemorrhage were the best predictors of child motor development at five years old (Hintz, Kenrick, Vohr, Poole, \& Higgins, 2006). 
Few developmental assessments target exclusively preterm infants, evaluating the very early time period before they reach term age. Preterm neonates are a special population exhibiting the physiological immaturity of a fetus but not protected within the uterine environment. In the Neonatal Intensive Care Unit (NICU), these infants are constantly challenged by a set of stressful stimuli, including noise, light, pain, and excessive handling, which are all inherent in intensive care treatment (Grunau, Holsti, \& Peters, 2006; Newnham, Inder, \& Milgrom, 2009). Usually the infants present a relevant health history including adverse events when they are discharged from the NICU.

Even as early as hospitalization, these infants need to be assessed effectively in order to detect early risks for later problems along the development pathway. There are few studies to date that focus on the neurodevelopment of preterm infants in the period from birth to term age. The Neurobehavioral Assessment of the Preterm Infant (NAPI) is an instrument developed in the United States to evaluate the neurodevelopment of preterm infants from 32 to 40 weeks PCA (Korner, Brown, Thom, \& Constantinou, 2000).

If the risks to vulnerable children within a population are detected very early in development, it will be easier to implement prevention strategies and policies for developmental research in childhood. As highlighted by Engle, Black and Berhman (2007) and Walker et al. (2007), risk factors often occur together or cumulatively, with a concomitant increase in adverse effects on development, especially in the developing countries.

Regarding the sex differences in developmental outcomes in the neonatal phase, few behavioral differences exist in healthy, full-term neonates assessed between 48 and 80 hours of life, according to the Brazelton Scale. However, females did achieve higher scores in the categories of orientation, animate auditory alertness, quality of alertness, and irritability (Boatelle-Costa, Costas-Moragas, Botet-Mussons, Fornieles-Deu, \& De Cáceres-Zurita, 2007). In addition, persistent male disadvantage was evident among the early childhood neurodevelopmental outcomes of extremely preterm infants born at $<28$ weeks and weighing $<1,000 \mathrm{~g}$ within 18-22 months corrected age (CA; Hintz et al., 2006). As far as we know, the sex specific effect on the preterm infant development has not been examined within the period from birth to term age.

The main objective of the present study was to examine the effect of the sex differences on very early neuro-development of infants born preterm at 32-37 weeks of post-conceptional age, in a developing country. In addition, it was compared the infants' neurobehavioral performance of the study-sample with the NAPI norm-reference standardized assessment of American infants.

\section{Method}

\section{Study Design}

This is a cross-sectional study with between-group comparisons.

\section{Participants}

The sample of the present study was 202 preterm and low birthweight infants (103 males and 99 females) aged from 32 to 37 weeks PCA, who were born in the Maternity Hospital of Goiania (Goiás, Brazil). This is level III hospital linked with the Public Health System for assisting low-income patients. The inclusion criteria were gestational age of $<37$ weeks, birthweight $<2,500 \mathrm{~g}$, absence of congenital anomalies and genetic defects, intraventricular hemorrhage grade III or IV, absence of assisted ventilation, and physiological stable clinical status as assessed by the NAPI. In the case of twins, only one infant was chosen for inclusion by random selection. From the initial eligible sample of 234 preterm and low birth weight infants, 32 infants were excluded from the study (19 infants by random selection in the case of twins, nine infants with birthweight $>2,500 \mathrm{~g}$, and four infants with clinical suspicion of congenital anomalies). Included in the study sample were $27(13 \%)$ infants of twin gestation (12 [12\%] females, 15 [15\%] males).

\section{Ethical Approval}

The study was approved by the Clinical Research Ethics Board of the General Hospital of Goiania (73/2004). Free and informed consent was obtained from all parents prior to participation in the study.

\section{Instruments and Measures}

Neurobehavioral Assessment of Preterm Infant (Korner et al., 2000). The NAPI is a standardized neurodevelopmental assessment of the progression of early neurobehavioral performance in preterm infants from 32 weeks PCA to term age of 38-40 weeks PCA (PCA: gestational age plus chronological age). This instrument includes the following seven clusters: scarf sign, motor development and vigor, popliteal angle, alertness and orientation, irritability, quality of cry, and percent sleep ratings. The measurement of an infant's neurodevelopmental performance in each cluster ranges from zero to 100 points. Early risk for abnormal neurodevelopment was assigned when cluster scores fell more than one standard deviation below the mean (Constantinou, AdamsonMacedo, Mirmiram, Ariagno, \& Fleisher, 2005). The face validity and sensitivity of the NAPI were described using an index of medical complications (Korner, 1996). The criteria validity has been examined by Majnemer and Snider (2005). The interrater reliability coefficient ranged from .67 to .97 (Korner et al., 1987). The sensitivity and specificity were $75 \%$ and $69 \%$, respectively, for the 
association between the NAPI and general movements (Constantinou et al., 2005).

Neonatal Medical Index (NMI; Korner et al., 1994). The NMI is a simple classification system used to summarize the medical course of preterm infants during hospitalization. NMI classifications fall in a crescent ordinal scale from I to $\mathrm{V}$, with higher numbers denoting more serious medical complications.

Clinical Risk Index for Babies (CRIB; Cockburn et al., 1993). The CRIB is used to assess neonatal clinical risk for morbidity and mortality during the first 12 hours of postnatal life. The CRIB score is calculated taking into account the following six variables: birthweight, gestational age, highest and lowest fractional inspired oxygen $\left(\mathrm{FiO}_{2}\right)$, highest base excess, and congenital anomalies. The highest score possible in this index is 24 points, with higher scores implying greater risk for morbid-mortality. A CRIB score $>4$ was the best predictor of mortality (Brito, Matsudo, Gonzalez, Carvalho, \& Ferrari, 2003).

Brazilian Association of Company of Search Questionnaire (Associação Brasileira de Empresas de Pesquisa [ABEP], 2000). Data based on the Socio-Economic Survey 2000 IBOPE (www.abep.org; abep@abep.org). This questionnaire assessed the socio-economic level of Brazilian families according to an ordinal scale of seven levels: A1 (score 30-34), A2 (25-29), B1 (21-24), B2 (1720), C (11-16), D (6-10), and E (zero-5). Higher scores in this questionnaire indicate higher socio-economic status.

\section{Procedures}

The NAPI was performed on clinically stable infants of 32-37 weeks PCA who were hospitalized in the Special Care Nursery. The assessments were carried out by trained physiotherapists and supervised by an expert examiner. The assessment was video-recorded with a digital camera (Mini DV Sony Digital Handycam Model DCR-HC40). Two examiners participated in each evaluation: one performed the infant assessment while the other videorecorded the exam. The length of each assessment was approximately 20 minutes, with evaluation of the infant occurring at least 60 minutes after feeding. Mothers were asked to participate in the socio-economic questionnaire, and medical charts were reviewed to obtain the relevant health history of the infants.

The NAPI scores of the study sample were calculated within a range of zero to 100 for PCA (32-37 weeks) and each of the seven clusters as proposed by the NAPI normative data. In addition, the number of changes in behavioral states during the test was noted. The cluster scores of the study sample then were converted into standard deviations. The NAPI test offers both the mean scores, the standard deviations $(S D)$, and the classifications concerning the standard deviations, as proposed by Korner et al. (2000). The classification is the following:
Low average performance $(S D>-1.0)$, Average performance ( $S D$ ranged from -.5 to .5$)$, and High average performance $(S D>1.0)$.

The videos were analyzed by two expert, independent coders in order to score the infants' neurodevelopmental performance. The coders were blinded to the health history of the infants. The percentage of agreement between the two coders was obtained through the following formula: agreement / (agreement + disagreement) $\times 100$. It was used 40 videos to calculate the percentage of agreement. The results showed an agreement of $88 \%$ in application of the NAPI scoring system.

Descriptive statistical analysis was performed. The between-groups comparison was conducted using the Student's $t$-test. The Statistical Package for Social Sciences (SPSS, version 17.0) was used for all data analysis with the exception of the comparison between the NAPI study-sample and the NAPI normative-sample. This comparison was performed using the InStat software ([DATASET1.ISD], demo version) which analyzed the data separated by PCA groups. The significance level was set at $5 \%(p \leq .05)$.

\section{Results}

\section{Characteristics of the Study Sample}

Table 1 shows that all infants were assessed within 35 weeks PCA (median; range 32-37 weeks). The study sample included infants born at a median of 33 weeks PCA (range 24-38 weeks), had a median birthweight of $1,610 \mathrm{~g}$, and were a median of $43 \mathrm{~cm}$ in length at birth. The mechanism of delivery was approximately equally distributed between cesarean section and vaginal delivery in the study sample. All infants presented a low risk for morbidity and mortality according to the neonatal clinical risk indexes of Apgar, CRIB, and NMI scores. The median five minute Apgar score was eight, although there was a broad range (1-10) within the study sample. There were no statistical differences between group comparisons regarding the neonatal characteristics of females $(n=99)$ and males $(n=103)$.

In Table 2, it is seen that a majority of the preterm infants were subjected to oxygen hood therapy $(85 \%)$ during hospitalization. In addition, some infants required other forms of respiratory assistance by means of nasal continuous positive airway pressure (CPAP) or oxygen support within the isolette. Only $5 \%$ of the infants needed mechanical ventilation at some point. The total time of hospitalization was a median of 27 days and ranged from five to 95 days. The female and male infants were similar in clinical status characteristics with no significant statistical differences between groups.

Table 3 presents the infants' family characteristics, displaying mainly young mothers of 23 years of age (median) with predominantly low educational levels. The majority of the mothers $(97 \%)$ and fathers $(93 \%)$ in the 
Gabriel, P. S. Z., Formiga, C. K. M. R. \& Linhares, M. B. M. (2013). Early Neurobehavioral Development of Preterm Infants.

sample completed an elementary or high school level education. The majority of the heads of the family were employed. The socio-economic statuses of the families were weighted predominantly in poorer stratifications in comparison to the medium levels (classes D1 plus $\mathrm{E}=$ $68 \%$; classes C plus B2 $=32 \%$ ). There were no significant statistical differences between groups differentiated by the sex variable.

\section{Neurobehavioral Developmental Outcome}

Infants born preterm at 32-37 weeks PCA displayed the following results in the NAPI assessment: 63 infants $(31 \%)$ were in the low average level, 132 infants $(65 \%)$ were average, and seven infants (4\%) were high average. Risk for later developmental problems as assessed by the NAPI was detected in $31 \%$ of the study sample.

Table 1

Characteristics of Preterm Infants - All Sample and Groups Distributed by Sex

\begin{tabular}{|c|c|c|c|c|}
\hline Characteristics of preterm infants & $\begin{array}{l}\text { All Sample } \\
(n=202)\end{array}$ & $\begin{array}{l}\text { Female } \\
(n=99)\end{array}$ & $\begin{array}{c}\text { Male } \\
(n=103)\end{array}$ & $p$-value \\
\hline Gestational age (weeks) - Median (range) & $33(24-36)$ & $33(27-36)$ & $33(24-36)$ & .64 \\
\hline \multicolumn{5}{|l|}{ Delivery } \\
\hline Cesarean section $-f\left(\%^{1}\right)$ & & & & \\
\hline Vaginal delivery $-f\left(\%^{1}\right)$ & $110(54) 92(46)$ & $43(43) 56(57)$ & $49(48) 54(25)$ & .57 \\
\hline Birthweight (grams) - Median (range) & $1,610(820-2,490)$ & $1,550(1,055-2,490)$ & $1,705(820-2,455)$ & .32 \\
\hline Lenght at birth $(\mathrm{cm})-$ Median (range) & $43(31-50)$ & $43(31-50)$ & $43(32-50)$ & .75 \\
\hline Appropriate size for Gestational age & & & & .60 \\
\hline $\mathrm{AGA}-f\left(\%^{1}\right)$ & $155(77)$ & $77(78)$ & $78(76)$ & \\
\hline $\mathrm{SGA}-f\left(\%^{1}\right)$ & $46(22)$ & $22(22)$ & $24(23)$ & \\
\hline LGA $-f(\%)$ & $1(1)$ & 0 & $1(1)$ & \\
\hline Apgar $5^{\text {th }}$ min - Median (range) & $8(1-10)$ & $8(2-10)$ & $8(1-10)$ & .38 \\
\hline CRIB - Median (range) & $0(0-5)$ & $0(0-5)$ & $0(0-4)$ & .18 \\
\hline NMI - Median (range) & $3(1-5)$ & $3(1-5)$ & $3(1-5)$ & .11 \\
\hline $\begin{array}{l}\text { Age at the day - assessment (Post-conceptional } \\
\text { age in weeks) - Median (range ) }\end{array}$ & $35(32-37)$ & $35(32-37)$ & $35(32-37)$ & .82 \\
\hline
\end{tabular}

Note. $f=$ frequence; $\%=$ prevalence $\%^{1}=$ percentage; $\mathrm{AGA}=$ Appropriate size for gestational age; SGA = Small for gestational age; $\mathrm{LGA}=$ Large for gestational age; $\mathrm{CRIB}=$ Clinical Risk Index for Babies; NMI= Neonatal Medical Index.

Table 2

Characteristics of the Infant Clinical Status During Hospitalization in the Neonatal Period - All Sample and Groups Distributed by Sex

\begin{tabular}{lcccc}
\hline Characteristics of the infant's clinical status & $\begin{array}{c}\text { All sample } \\
(n=202)\end{array}$ & $\begin{array}{c}\text { Female } \\
(n=99)\end{array}$ & $\begin{array}{c}\text { Male } \\
(n=103)\end{array}$ & $p$-value \\
\hline $\begin{array}{l}\text { Respiratory assistance } \\
\quad \text { Oxygen therapy Hood }-f(\%)\end{array}$ & $172(85)$ & $83(8)$ & $89(86)$ & .69 \\
$\quad$ Nasal CPAP $-f(\%)$ & $118(58)$ & $55(56)$ & $63(61)$ & .48 \\
$\quad \begin{array}{l}\mathrm{O}_{2} \text { support in the isolete }-f(\%) \\
\text { Intubated }-f(\%)\end{array}$ & $40(20)$ & $19(19)$ & $21(20)$ & .86 \\
$\begin{array}{l}\text { Length time NICU (days) } \\
\quad \text { Median (range) }\end{array}$ & $5(0-60)$ & $5(5)$ & $6(6)$ & 1.00 \\
$\begin{array}{l}\text { Length time in NMRU } \\
\quad \text { Median (range) }\end{array}$ & $8(0-60)$ & $8(0-42)$ & $7(0-60)$ & .37 \\
$\begin{array}{l}\text { Length time in Infirmary } \\
\quad \text { Median (range) }\end{array}$ & $8(0-36)$ & $7(0-36)$ & $7(0-32)$ & .37 \\
$\begin{array}{l}\text { Total time in the hospital } \\
\quad \text { Median (range) }\end{array}$ & $27(5-95)$ & $24(5-68)$ & $21(6-95)$ & .96 \\
\hline
\end{tabular}

Note. $f=$ frequence $\%=$ prevalence $\mathrm{CPAP}=$ continuous positive airway pressure; $\mathrm{NICU}=$ Neonatal Intensive $\mathrm{Care}$ Unit; $\mathrm{NMRU}=$ Neonatal Medium Risk Unit. 
Table 3

Characteristics of the Infants' Family

\begin{tabular}{|c|c|c|c|c|}
\hline Characteristics of the infants' family & $\begin{array}{l}\text { All Sample } \\
\quad(n=202)\end{array}$ & $\begin{array}{c}\text { Female } \\
(n=99)\end{array}$ & $\begin{array}{c}\text { Male } \\
(n=103)\end{array}$ & $p$-value \\
\hline Mothers' age (years) - Median (range) & $23(14-43)$ & $25(14-43)$ & $23(14-42)$ & .29 \\
\hline Mothers' educational level $-f\left(\%^{1}\right)$ & & & & .27 \\
\hline Elementary school & $98(49)$ & $48(49)$ & $50(48)$ & \\
\hline High school & $97(48)$ & $48(48)$ & $49(47)$ & \\
\hline Undergarduated & $7(3)$ & $3(2)$ & $4(4)$ & \\
\hline Fathers' educational level $-f\left(\%^{1}\right)$ & & & & .97 \\
\hline Illiterate & $6(3)$ & $3(3)$ & $3(3)$ & \\
\hline Elementary school & $136(68)$ & $69(70)$ & $67(66)$ & \\
\hline High school & $52(25)$ & $24(24)$ & $28(28)$ & \\
\hline Undergraduated & $8(4)$ & $3(3)$ & $5(3)$ & \\
\hline Ocupational of the head of the family $-f\left(\%^{1}\right)$ & & & & 1.00 \\
\hline Employed & $192(95)$ & $94(95)$ & $98(95)$ & \\
\hline Unemployed & $10(5)$ & $5(5)$ & $5(5)$ & \\
\hline Socio-economic status ${ }^{3}-f\left(\%^{1}\right)$ & & & & .63 \\
\hline Class E & $39(19)$ & $18(18)$ & $21(20)$ & \\
\hline Class D1 & $98(49)$ & $45(46)$ & $53(52)$ & \\
\hline Class C & $53(26)$ & $30(30)$ & $23(22)$ & \\
\hline Class B2 & $12(6)$ & $6(6)$ & $6(6)$ & \\
\hline
\end{tabular}

Note. $f=$ frequence; $\%=$ prevalence; $\%=$ percentage $;{ }^{2}$ minimum income in Brazil at the data collection (real) $\mathrm{R} \$ 300.00$; ${ }^{3} \mathrm{ABEP}(2000)$.

Table 4 shows that there were some significant statistical differences between the study sample and NAPI sample with regard to scores obtained in the scarf sign, motor development and vigor, alertness and orientation, quality of cry, and percent sleep ratings clusters. There were no differences between groups in the popliteal angle and irritability categories. The study sample infants presented less muscle tone in the scarf sign category in comparison to the NAPI sample at 34,35 , and 36 weeks PCA. In the motor development and vigor cluster, study sample infants presented with less vigor and spontaneous movement in comparison to the NAPI sample for all PCAs analyzed. In the alertness and orientation cluster, study sample infants showed higher alertness and better orientation than infants of the NAPI sample at 33 and 35 weeks PCA. In the quality of cry cluster, study sample infants exhibited weaker cries than the NAPI sample at 33, 34, 35, and 36 weeks PCA. The infants of the study sample remained in a longer sleep state during the NAPI assessment in comparison with the NAPI sample for all PCAs.

Table 5 displays that there were no statistically significant differences between groups differentiated by sex in all cluster scores of the NAPI assessment. The female and male preterm infants of the study sample presented with similar performance patterns in the scarf sign, motor development and vigor, popliteal angle, alertness and orientation, irritability, quality of cry, and percent sleep ratings clusters. 
Gabriel, P. S. Z., Formiga, C. K. M. R. \& Linhares, M. B. M. (2013). Early Neurobehavioral Development of Preterm Infants.

Table 4

NAPI Score (Mean and Standard Deviation), Regarding the Infants' Post-Conceptional Age - All Study Sample and NAPI Sample Comparison Between Groups

\begin{tabular}{|c|c|c|c|c|c|c|c|}
\hline \multirow[t]{2}{*}{ NAPI Clusters } & \multirow[t]{2}{*}{$\begin{array}{l}\text { Post-conceptional } \\
\text { Age (weeks) }\end{array}$} & \multicolumn{2}{|c|}{$\begin{array}{l}\text { All Study Sample } \\
\text { (S-S) }\end{array}$} & \multicolumn{2}{|c|}{$\begin{array}{l}\text { NAPI Sample } \\
\text { (S-NAPI) }\end{array}$} & \multirow[t]{2}{*}{$t$} & \multirow[t]{2}{*}{$p$-value } \\
\hline & & Mean & $S D( \pm)$ & Mean & $S D( \pm)$ & & \\
\hline \multirow[t]{6}{*}{ Scarf Sign } & 32 & 33.3 & 0 & 38.2 & 12.2 & NA & NA \\
\hline & 33 & 36.5 & 15.8 & 42.2 & 14.7 & 1.90 & .06 \\
\hline & 34 & 35.7 & 12.6 & 47.3 & 15.1 & 5.20 & $<.001$ \\
\hline & 35 & 39.4 & 13.0 & 51.7 & 16.1 & 5.99 & $<.001$ \\
\hline & 36 & 40.5 & 17.8 & 55.9 & 17.8 & 4.74 & $<.001$ \\
\hline & 37 & 52.4 & 27.0 & 60.1 & 15.0 & 1.27 & .22 \\
\hline Motor & 32 & 33.0 & 12.9 & 47.5 & 12.9 & NA & NA \\
\hline \multirow{5}{*}{$\begin{array}{l}\text { Development } \\
\text { and Vigor }\end{array}$} & 33 & 35.9 & 13.5 & 51.3 & 14.7 & 5.32 & $<.001$ \\
\hline & 34 & 41.2 & 16.7 & 57.1 & 14.8 & 6.86 & $<.001$ \\
\hline & 35 & 47.8 & 14.5 & 60.0 & 13.0 & 6.09 & $<.001$ \\
\hline & 36 & 48.3 & 15.4 & 63.0 & 14.5 & 5.48 & $<.001$ \\
\hline & 37 & 51.4 & 14.9 & 67.6 & 10.9 & 4.72 & $<.001$ \\
\hline \multirow[t]{6}{*}{ Popliteal Angle } & 32 & 22.2 & 19.2 & 21.6 & 22.7 & NA & NA \\
\hline & 33 & 29.0 & 20.6 & 22.9 & 25.6 & 1.24 & .22 \\
\hline & 34 & 35.7 & 25.6 & 32.8 & 29.5 & .67 & .50 \\
\hline & 35 & 36.3 & 22.5 & 36.8 & 29.2 & .13 & .90 \\
\hline & 36 & 35.1 & 24.8 & 41.7 & 27.8 & 1.32 & .19 \\
\hline & 37 & 42.9 & 18.7 & 43.1 & 32.3 & .05 & .96 \\
\hline \multirow{6}{*}{$\begin{array}{l}\text { Alertness } \\
\text { and Orientation }\end{array}$} & 32 & 45.2 & 33.5 & 42.3 & 15.9 & NA & NA \\
\hline & 33 & 51.8 & 20.3 & 43.0 & 20.5 & 2.15 & .03 \\
\hline & 34 & 51.2 & 23.3 & 48.6 & 19.9 & .81 & .42 \\
\hline & 35 & 61.4 & 19.4 & 51.5 & 19.2 & 3.42 & $<.001$ \\
\hline & 36 & 56.4 & 19.8 & 54.0 & 19.4 & .66 & .51 \\
\hline & 37 & 56.9 & 18.2 & 57.7 & 18.0 & .20 & .85 \\
\hline \multirow[t]{6}{*}{ Irritability } & 32 & 16.7 & 16.7 & 34.0 & 15.5 & NA & NA \\
\hline & 33 & 28.7 & 21.6 & 33.6 & 19.2 & 1.26 & .21 \\
\hline & 34 & 29.4 & 26.6 & 36.6 & 20.6 & 1.87 & .07 \\
\hline & 35 & 36.4 & 25.9 & 41.0 & 16.9 & 1.25 & .22 \\
\hline & 36 & 39.5 & 25.9 & 41.5 & 20.4 & .45 & .65 \\
\hline & 37 & 42.8 & 19.9 & 47.2 & 17.9 & 1.00 & .32 \\
\hline \multirow[t]{6}{*}{ Cry Quality } & 32 & 0 & 0 & 41.1 & 25.2 & NA & NA \\
\hline & 33 & 25.8 & 33.8 & 40.9 & 26.8 & 2.32 & .03 \\
\hline & 34 & 22.7 & 35.8 & 50.5 & 28.2 & 5.32 & $<.001$ \\
\hline & 35 & 39.1 & 43.8 & 54.2 & 28.1 & 2.44 & .02 \\
\hline & 36 & 37.8 & 44.7 & 63.4 & 24.2 & 3.37 & .002 \\
\hline & 37 & 54.8 & 41.5 & 59.8 & 22.8 & .54 & .59 \\
\hline Percent Asleep & 32 & 76.2 & 41.2 & 33.6 & 24.3 & NA & NA \\
\hline \multirow[t]{5}{*}{ Ratings } & 33 & 60.1 & 32.9 & 35.7 & 26.9 & 4.35 & $<.001$ \\
\hline & 34 & 58.9 & 33.8 & 31.0 & 28.8 & 6.12 & $<.001$ \\
\hline & 35 & 48.0 & 30.7 & 31.0 & 26.8 & 4.08 & $<.001$ \\
\hline & 36 & 48.2 & 31.3 & 29.2 & 28.8 & 3.56 & $<.001$ \\
\hline & 37 & 38.7 & 32.8 & 22.5 & 23.7 & 2.15 & .04 \\
\hline
\end{tabular}

Note. For infants 32 weeks conceptional age: $N=3$ (S-S) and $N=51$ (S-NAPI); 33 weeks: $N=31$ (S-S) and $N=131$ (S-NAPI); 34 weeks: $N=55$ (S-S) and $N=200$ (S-NAPI); 35 weeks: $N=55$ (S-S) and $N=224$ (S-NAPI); 36 weeks: $N=37$ (S-S) and $N=161$ (SNAPI); 37 weeks: $N=21$ (S-S) and $N=99$ (S-NAPI); NA= no applicable. 
Table 5

NAPI Score (Mean and Standard Deviation; Median and Range) - Female and Male Infants Comparison Between Groups

\begin{tabular}{|c|c|c|c|c|c|c|}
\hline \multirow[b]{2}{*}{ NAPI Clusters } & \multicolumn{2}{|c|}{ Female $(n=99)$} & \multicolumn{2}{|c|}{ Male $(n=103)$} & \multirow[b]{2}{*}{$t$} & \multirow[b]{2}{*}{$p$-value } \\
\hline & $\begin{array}{l}\text { Median } \\
\text { (range) }\end{array}$ & $\begin{array}{l}\text { Mean } \\
S D\end{array}$ & $\begin{array}{l}\text { Median } \\
\text { (range) }\end{array}$ & $\begin{array}{c}\text { Mean } \\
S D\end{array}$ & & \\
\hline Scarf Sign & $\begin{array}{c}33.3 \\
(0-100)\end{array}$ & $\begin{array}{c}38.7 \\
\pm 15.6\end{array}$ & $\begin{array}{c}33.3 \\
(0-100)\end{array}$ & $\begin{array}{c}40.1 \\
\pm 17.7\end{array}$ & -.60 & .55 \\
\hline Motor Development and Vigor & $\begin{array}{c}41.4 \\
(12.2-85.5)\end{array}$ & $\begin{array}{c}44.4 \\
\pm 15.8\end{array}$ & $\begin{array}{c}40.9 \\
(8.2-86)\end{array}$ & $\begin{array}{c}44.5 \\
\pm 16.0\end{array}$ & -.03 & .97 \\
\hline Popliteal Angle & $\begin{array}{c}33.3 \\
(0-100)\end{array}$ & $\begin{array}{c}32.7 \\
\pm 23.8\end{array}$ & $\begin{array}{c}33.3 \\
(0-100)\end{array}$ & $\begin{array}{c}37.9 \\
\pm 22.4\end{array}$ & -1.60 & .11 \\
\hline Alertness and Orientation & $\begin{array}{c}58.1 \\
(9.3-93.5)\end{array}$ & $\begin{array}{c}55.6 \\
\pm 21.7\end{array}$ & $\begin{array}{c}60.9 \\
(2.4-89.2)\end{array}$ & $\begin{array}{c}55.4 \\
\pm 20.4\end{array}$ & .05 & .96 \\
\hline Irritability & $\begin{array}{c}38.1 \\
(0-82.2)\end{array}$ & $\begin{array}{c}36.0 \\
\pm 26.3\end{array}$ & $\begin{array}{c}36 \\
(0-75)\end{array}$ & $\begin{array}{c}32.5 \\
\pm 23.9\end{array}$ & .98 & .33 \\
\hline Cry Quality & $\begin{array}{c}0 \\
(0-100)\end{array}$ & $\begin{array}{c}36.9 \\
\pm 42.6\end{array}$ & $\begin{array}{c}0 \\
(0-100)\end{array}$ & $\begin{array}{c}30.1 \\
\pm 39.2\end{array}$ & 1.17 & .24 \\
\hline Percent Asleep Ratings & $\begin{array}{c}57.2 \\
(0-100)\end{array}$ & $\begin{array}{c}52.9 \\
\pm 34.4\end{array}$ & $\begin{array}{c}50 \\
(0-100)\end{array}$ & $\begin{array}{c}51.7 \\
\pm 31.4\end{array}$ & .26 & .79 \\
\hline Number of Behavioral States Changes & $\begin{array}{c}5 \\
(0-11)\end{array}$ & $\begin{array}{c}4.6 \\
\pm 2.1\end{array}$ & $\begin{array}{c}4 \\
(0-8)\end{array}$ & $\begin{array}{c}4.3 \\
\pm 1.9\end{array}$ & .84 & .40 \\
\hline
\end{tabular}

Note. $S D=$ Standard Deviation.

\section{Discussion}

Despite the higher risk for developmental problems in preterm infant males than females (Hintz et al., 2006), the neurobehavioral development of male and female infants of the present study presented a similar pattern in very early neurobehavioral development. There were no differences between groups differentiated by gender in all NAPI clusters in the preterm infants assessed during the neonatal period prior to term age.

In contrast, the full-term infants studied by BoatelleCosta et al. (2007) displayed gender differences using the Brazelton Neonatal Behavioral Assessement Scale at approximately 60 hours of postnatal life. In this study, the females had higher scores than males in orientation, animate auditory, alertness, quality of Alertness, and irritability domains. Otherwise, they were able to regulate better their states and return to a calmer condition more often than the males. Additionally, the male preterm infants exhibited developmental disadvantages in comparison to female infants at 18 to 22 months CA. Male infants possessed an elevated chance of developing cerebral palsy only in the absence of intraventricular hemorrhage. Male sex associated with health risk factors was predictive of lower scores in child motor development at five years of age (Janssen et al., 2009).

Taken together, the results of these two studies showed sex differences in more advanced postnatal ages than the ages analyzed in the present study. Our data of similar neurobehavioral patterns in male and female infants could suggest that the infants in the period of very early development suffer less from the influence of social and environmental variables, which explains the different sex responses of the neonates. As the infants advance in their developmental course, the chance of gender differences should increase related to the social and cultural contextual influences or due to hormonal factors.

Regarding the comparison of the study-sample of Brazilian preterm infants at 32-37 weeks PCA with the norm-reference of American infants, it was found significant statistical differences in the NAPI cluster scores of scarf sign, motor development and vigor, alertness and orientation, quality of cry, and percent sleep.

The study sample exhibited lower muscle tone on the scarf sign assessment than the standardized NAPI sample at 34, 35, and 36 weeks PCA. This finding is consistent with the results of Lekskulchai and Cole (2000b) for infants at the same age as our study sample. They found that preterm infants aged 28 to 31 weeks PCA recorded a lower scarf ratio than did infants who were older (32 to 40 weeks PCA). The scarf ratio increased with age, and infants displayed increasing resistance to passive movement of the arm with increasing age, which is thought to be associated with improving muscle tone of the upper trunk and limbs. The scarf sign as assessed at 36 to 40 weeks PCA was positively correlated with higher levels on the motor performance assessment at 1, 2, 3, and 4 months of age adjusted for prematurity. This sign assessed at term age was found to have good validity indices for diagnostic testing as well as a significant relationship to 
active movement of the arm at four months adjusted age (Lekskulchai \& Cole, 2000a). Ohgi, Gima, and Ariyama (2006) found that spontaneous upper extremity movements of premature infants have nonlinear, chaotic, and dynamic characteristics. The authors suggested that motor development leads to the process of self-organization on the basis of chaotic dynamics, which may reflect the processes of subsystems such as the central nervous system, sensory perception, musculoskeletal system, and the environment.

The motor development and vigor performance of the preterm infants in the present study sample showed lower spontaneous movements in all ages in comparison to the NAPI standard sample. In the NAPI scale, the motor and vigor cluster included sets of different movements, including forearm recoil, ventral suspension, prone head raising, spontaneous crawling, power of active movements (legs and arms), and vigor of spontaneous movements.

In comparison to the NAPI assessment, motor development is usually evaluated in different domains, using different assessment instruments, and in ages later than neonatal phase of the child development pathway. For example, the study of Chaudhari and Deo (2006) assessed infants with a gestational age of $>37$ weeks, birth weight $>2,500 \mathrm{~g}$, normal antenatal and perinatal course, and normal delivery through the use of the Amiel-Tison neurological test at 3, 6, 9, and 12 months of age. This test focused on the assessment of motor domains of primitive reflexes, head control, sitting without support, passive and active tone, popliteal angle, and adductor angle hip through the use of goniometry.

The study of Eliakim, Nemet, Friedland, Dolfin and Regev (2002) assessed bone strength in the lower extremities in three cases of preterm and very low birth weight infants with central nervous system pathology and showed reduced unilateral spontaneous leg movements as evaluated through the use of ultrasound measurements of the bilateral tibia. They found that reduced spontaneous activity of one leg due to brain pathology resulted in decreased tibial activity in the affected side. They concluded that spontaneous movements (mainly antigravity, flexion, and extension) are relevant for bone structure and mineralization in very low birth weight premature infants. Both Eliakim's study and the present study have similar results independently of the absence of brain disease in our sample study.

Biological factors may influence motor development in preterm infants when postnatal weight, height, and head circumference are insufficient (Marlow, 2004). In addition, small muscle size, lower proportion of fasttwitch muscle fibers, reduced intramuscular high-energy phosphate, and physical hypoactivity may cause the anaerobic performance of preterm infants to be lower than in term infants (Bartlett \& Fanning, 2003). Poor muscle coordination, strength, power regulation, and, as a result, inadequate postural control, can affect the quality of movements and result in a delayed onset of antigravity activities, particularly in preterm infants (Keller, Bar-Or, Kriemler, Ayub, \& Saigal, 2000).

With respect to the NAPI cluster of alertness and orientation, the study sample infants displayed higher alertness and orientation to inanimate and animate stimuli than the NAPI standard sample at 33 and 35 weeks PCA. Our sample included only three children with extremely low birth weight, whereas in the NAPI sample we could not identify the infant birthweight variable which may explain the differences between the two samples.

Comparing our study with the results of Constantinou et al. (2005), the alertness and orientation score was similar to the NAPI score (around 56) in very low birthweight infants but was higher than the scores of the extremely birthweight infants at 36 weeks PCA. The preterm infants ( $<30$ gestational age) weighing $<1,250 \mathrm{~g}$ studied by Ariagno et al. (1997) presented with similar results to the present study sample in alertness and orientation to stimuli domain, though they had different results in the sleep-awake state.

The infants of the present study spent more time sleeping during the assessment in all age groups in comparison to the NAPI standard sample. When awake, however, they remained alert and attentive. In contrast, Ariagno et al. (1997) found that the infants spent a smaller percentage of time sleeping during the assessment and were more irritable when awake. This state of sleep-wake transition is expected to increase until 40 weeks and decrease after 43 weeks CA (Holditch-Davis, Scher, Schwartz, \& Hudson-Barr, 2004). Active waking, active sleeping, negative facial expressions, and quiet sleep regularity also showed changes after reaching term age. It could be speculated that the preterm infants who stayed asleep for most of the assessment could have also presented with a hypotonic pattern and low performance in scarf sign and motor development and vigor outcomes.

In the irritability domain, including quality of crying, the study sample was similar to the NAPI sample. Otherwise, the quality of crying of the preterm infants of the study sample was lightly weak at $33,34,35$, and 36 weeks PCA in comparison to the moderate quality of crying in the infants of the standardized NAPI sample. We have to be cautious when interpreting the quality of crying used in the NAPI assessment, because it is not analyzed using precise parameters such as intensity, frequency, and pitch, as is seen in other studies (Rautava et al., 2007; Rothganger, 2003). The levels of crying in the low-risk preterm infants were related to irritability with hyperresponsivity and poor self-regulation state (Ohgi, Morita, Loo, \& Mizuike, 2008).

The present study has some limitations. The NAPI sample included infants in the American hospital, which is different from the Brazilian setting. Social and cultural variables may influence the comparison results between the developmental variables. The context of the hospital was not controlled with regard to environmental stimuli 
such as sound and light which could have affected the neonates. Additionally, the prenatal risk of the infants was not examined as the neonatal risk variables were.

Nonetheless, the findings of the present study contribute to a better framework for understanding the neurobehavioral pattern (from birth to term age) of healthy preterm infants of a developing country in comparison to a sample from a developed country. The data obtained from the present study may be useful for new studies concerning similar preterm infant samples in other developing countries. Strategies and policies should be implemented as early as possible to protect child development before the preschool age in order to avoid the loss of full developmental potential, as highlighted by Engle et al. (2007).

Future studies should address the NAPI standardization using preterm infant samples of different regions in order to broaden the psychometric properties of the instrument. In addition, the associations between neurodevelopmental outcomes, prenatal risks, and neonatal problems merit further exploration. A psychometric study of the predictive validity of NAPI for child developmental outcomes in different ages could be designed in the future.

\section{References}

Ariagno, R. L., Thoman, E. B., Boeddiker, M. A., Kugener, B., Constantinou, J. C., Mirmiran, M., et al. (1997). Developmental care does not alter sleep and development of premature infants. Pediatrics, 100(6), 1-7.

Associação Brasileira de Empresas de Pesquisa. (2000). Critério de classificação econômica Brasil. Retrieved from http:/ /www.abep.org

Bartlett, D. J., \& Fanning, J. E. (2003). Use of the Alberta Infant Motor Scale to characterize the motor development of infants born preterm at eight months corrected age. Physicals Occupational Therapy and Pediatrics, 23(4), 31-45.

Bayley, N. (1993). The Bayley Scales of Infant Development ( $2^{\text {nd }}$ ed.). San Antonio, TX: The Psychological Corporation.

Boatelle-Costa, E., Costas-Moragas, C., Botet-Mussons, F., Fornieles-Deu, A., \& De Cáceres-Zurita, M. L. (2007). Behavioral gender differences in the neonatal period according to the Brazelton Scale. Early Human Development, 83(2), 91-97.

Brito, A., Matsudo, T., Gonzalez, M. R., Carvalho, A. B. R. C., \& Ferrari L. S. L. (2003). Escore CRIB, peso ao nascer e idade gestacional. Revista de Saúde Pública, 37(5), 597-602.

Chaudhari, S., \& Deo, B. (2006). Neurodevelopmental assessments in the first year with emphasis on evolution of tone. Indian Pediatrics, 43(6), 527-534.

Cockburn, F., Cooke, R. W. I., Gamsu, H. R., Greenouhg, A., Hopkins, A., Mcintosh, N., et al. (1993). The CRIB (clinical index for babies) score: A tool for assessing initial neonatal risk and comparing performance of neonatal care units. The Lancet, 342, 193-198.

Constantinou, J. C., Adamson-Macedo, E. M., Mirmiran, M., Ariagno, R. L., \& Fleisher, B. E. (2005). Neurobehavioral assessment predicts differential outcome between VLBW and ELBW preterm infants. Journal Perinatology, 25(12), 788-793.
Eliakim, A., Nemet, D., Friedland, O., Dolfin, T., \& Regev, R. H. (2002). Spontaneous activity in premature infants affects bone strength. Journal Perinatology, 22(8), 650-652.

Engle, P., Black, M. N., \& Berhman, J. R. (2007). Child development in developing countries 3: Strategies to avoid the loss of developmental potential in more than 200 million children in the developing world. The Lancet, 369, 229-242.

Gray, J. E., Richardson, D. K., \& McCormick, M. C. (1992). Score for neonatal acute physiology (SNAP) and risk of intraventricular hemorrhage (IHV). Pediatric Research, 31, 249.

Grunau, R. E., Holsti, L., \& Peters, J. W. B. (2006). Long-term consequences of pain in human neonates. Seminars in Fetal and Neonatal Medicine, 11(4), 293-300.

Hintz, S. R., Kenrick, D. E., Vohr, B. R., Poole, W. K., \& Higgins, R. D. (2006). Gender differences in neurodevelopmental outcomes among extremely preterm, extremely-lowbirthweight infants. Acta Paediatrica, 95(10), 1239-1248.

Holditch-Davis, D., Scher, M., Schwartz, T., \& Hudson-Barr, D. (2004). Sleeping and waking state development in preterm infants. Early Human Development, 80, 43-64.

Janssen, A. J. W. M., Saden, M. W. G. N., Akkermans, R. P., Tissingh, J., Oostendorp, R. A. B., \& Kollée L. A. A. (2009). A model to predict motor performance in preterm infants at 5 years. Early Human Development, 85(9), 599-604.

Keller, H., Bar-Or, O., Kriemler, S., Ayub, B. V., \& Saigal, S. (2000). Anaerobic performance in 5-to-7-years-old children of low birthweight. Medicine and Science in Sports and Exercise, 32(2), 278.

Koldewijn, K., Wolf, M. J., Wassenaer, A.V., Meijssen, D., Sonderen, L. V., Baar, A. V., et al. (2009). The infant behavioral assessment and intervention program for very low birth weight infants at 6 months corrected age. Journal of Pediatrics, 154(1), 33-38.

Korner, A. F. (1996). Reliable individual differences in preterm infants' excitation management. Child Development, 67(4), 1793-1805.

Korner, A. F., Brown, J. V., Thom, V. A., \& Constantinou, J. C. (2000). The neurobehavioral assessment of the preterm infant. Manual revised ( $2^{\text {nd }}$ ed.). Van Nuys, CA: Child Development Media.

Korner, A. F., Kraemer, H. C., Read, E. P., Forrest, T., Dimiceli, S., \& Thom, V. A. (1987). A methodological approach to developing an assessment procedure for testing the neurobehavioral maturity of preterm infants. Child Development, 58(6), 1478-1487.

Korner, A. F., Stevenson, D. K., Forrest, T., Constantinou, J. C., Dimiceli, S., \& Brown, B. W. M. (1994). Preterm medical complications differentially affect neurobehavioral functions: Results from a new neonatal medical index. Infant Behavior Development, 17(1), 37-43.

Lekskulchai, R., \& Cole, J. (2000a). The relationship between the scarf ratio and subsequent motor performance in infants born preterm. Pediatric Physical Therapy, 12(4), 150-157.

Lekskulchai, R., \& Cole, J. (2000b). Scarf Ratio: A method of measuring the scarf sign in preterm born infants. Australian Journal of Physiotherapy, 46(2), 85-90.

Majnemer, A., \& Snider, L. (2005). A comparison of developmental assessments of the newborn and young infant. Developmental Disabilities Research Reviews, 11(1), 68-73.

Marlow, N. (2004). Neurocognitive outcome after very preterm birth. Archives of Disease Child Fetal Neonatal, 89(3), 224-228. 
Newnham, C. A., Inder, T. E., \& Milgrom, J. (2009). Measuring preterm cumulative stressors within the NICU: The neonatal infant stressor scale. Early Human Development, 85(9), 549555.

Ohgi, S., Gima, H., \& Ariyama, T. (2006). Neonatal behavioral profile and crying in premature infants at term age. Acta Paediatrics, 95(11), 1375-1380.

Ohgi, S., Morita, S., Loo, K. K., \& Mizuike, C. (2008). Time series analysis of spontaneous upper-extremity movements of premature infants with brain injuries. Physical Therapy, 88(9), 1022-1033.

Piper, M. C., Pinnell, L. E., Darrah, J., Maguire, T., \& Byrne, P. J. (1992). Construction and validation of The Alberta Infant Motor Scale (AIMS). Journal of Public Health, 83(2), 546550.

Rautava, L., Lempinen, A., Ojala, S., Parkkola, R., Rikalainen, H., Lapinleimu, H., et al. (2007). Acoustic quality of cry in very-low-birth-weight infants at the age of $1 \frac{1}{2}$ years. Early Human Development, 83(1), 5-12.

Reuner, G., Hassenpflug, J. P., \& Philippi, H. (2009). Longterm development of low-risk low birth weight preterm born infants: Neurodevelopmental aspects from childhood to late adolescence. Early Human Development, 85(7), 409-413.

Rothganger, H. (2003). Analysis of the sounds of the child in the first year of age and a comparison to the language. Early Human Development, 75(1-2), 55-69.

Roze, E., Kerstjens, J. M., Maathuis, C. G. B., Horst, H. J., \& Bos, A. F. (2008). Risk factors for adverse outcome in preterm infants with periventricular hemorrhagic infarction. Pediatrics, 122(1), 46-52.

Walker, S. P., Wachs, T. D., Gardner, J. M., Lozoff, B., Wasserman, G. A., Pollitt, E., et al. (2007). Child development in developing countries 2. Child development: Risk factors for adverse outcomes in developing countries. The Lancet, $369,145-157$. 